\title{
Memorização para performance da "Máquina de Escrever" da Mini Suíte das Três Máquinas de Aylton Escobar: uma abordagem a partir do timbre
}

\author{
Memorization for performance of the piece \\ "máquina de escrever" (mini suíte das três máquinas) \\ from Aylton Escobar: an approach based on timbre
}

por Bibiana Maria Bragagnolo

RESUMO

0 presente trabalho tem como objetivo propor uma forma de memorização de música contemporânea para performance, mais especificamente, da "Máquina de Escrever" (Mini-Suite das Três Máquinas), de Aylton Escobar. Para tanto, foi aplicado um modelo de memorização baseado na sonoridade (timbres), tendo como referencial teórico principal a obra de Chaffin (2002) sobre memorização através de guias de execução.

Palavras-chave memorização; música contemporânea; guias de execução; Aylton Escobar, timbre

ABSTRACT

This paper aims to propose a memorization model for contemporary music for the performance of the piece "Máquina de Escrever" (from the Mini Suite das Três Máquinas), from Aylton Escobar. A memorization model based on the sonority (timbres) was applied using as principal reference Chaffin's work (2002) about memorization through performance cues.

Keywords memorization; contemporary music; performance cues;

Aylton Escobar; timbre 


\section{Introdução}

0 século XX trouxe na música uma série de transformações estéticas e mudanças de paradigmas. A partir da dissolução da tonalidade como valor único e da valorização de outros aspectos, a música caminhou para uma mudança de perspectiva sem igual, que pode ser descrita como a transição da civilização do tom para uma civilização do som (SOLOMOS, 2011, p. 19).

De acordo com Solomos (2011, p. 19), este caminho do tom ao som se deu em virtude da mudança de perspectiva em três aspectos, sendo o primeiro deles o timbre, que acabou por se emancipar e ganhar uma importância maior. A questão timbrística no início do século XX teve como base dois paradigmas, o da "ressonânica", que trata de prolongar a harmonia no timbre (com exemplo na obra de Debussy) e o da melodia de timbre, lançado por Schoenberg, onde a ideia era substituir a altura pelo timbre (SOLOMOS, 2011, p. 19). 0 segundo aspecto que Solomos coloca é o abandono da oposição som musical/ruído (2011, p. 20). Para o autor coube à música moderna "libertar o ruído, musicalmente falando, ou seja, reconhecer o seu potencial musical" (2008, p. 1). 0 terceiro aspecto pontuado por Solomos, por fim, é a passagem do modelo organizacionista ao modelo construtivista, no qual "em vez de compor com sons, compõe-se o som" (SOLOMOS, 2011, p. 20). Em síntese, o século XX trouxe novos paradigmas e com eles uma nova estética musical, "na qual a sonoridade se torna, plenamente, uma dimensão da sua escrita" (GUIGUE, 2011, p. 25).

Dentro do contexto acima descrito, na escrita pianística contemporânea, mais especificamente, o elemento timbrístico nos revelou novos potenciais extraídos do piano "com usos inovadores de pedal, pedal de dedo, clusters, uso do interior do piano e efeitos sonoros como glissandos e harmônicos" (BARANKOSKI, 2004, p. 103). Desta nova perspectiva, aliada à potencialidade da variação timbrística como elemento expressivo (HOLMES, 2012), surgiu o pressuposto de se pensar em uma forma de memorização ancorada pela sonoridade. A peça "A Máquina de Escrever", de Aylton Escobar, foi escolhida para este estudo devido ao fato de ser uma obra contemporânea de escrita não convencional, dentro do contexto de sonoridade anteriormente descrito. Além disso, a peça utiliza-se de efeitos sonoros não usuais na escrita pianística tradicional e também de efeitos sonoros criados a partir de elementos recorrentes na literatura para piano, que aparecem nesta obra com funções outras. Todos estes elementos peculiares da escrita da peça vêm ao encontro da finalidade investigativa deste trabalho, que tem como objetivo principal, a partir do referencial teórico escoIhido, propor uma forma de memorização baseada na sonoridade para performance da "Máquina de Escrever" da Mini Suíte das Três Máquinas, de Aylton Escobar.

\section{Considerações sobre a peça}

0 compositor paulista Aylton Escobar (1943) tem como característica marcante em 
sua obra a linguagem musical multifacetada que reflete com precisão a linguagem musical universal do século XX'. Segundo Del Pozzo, o compositor posiciona-se em lugar de destaque na linguagem musical universal, devido à sua postura de usar diversas tendências na sua obra para piano: atonalismo, técnica dos doze sons, indeterminação e eletroacústica (DEL POZZO, 2001, p. 4).

A Mini Suite das Três Máquinas (1970) é composta por três movimentos: "Máquina de Escrever", "Caixinha de Música" e "0 Coração da Gente". Na contracapa da partitura o compositor oferece informações sobre a obra, que são de grande valia para 0 intérprete, pois revelam o caráter e possibilidades interpretativas da peça:

Mini Suíte das Três Máquinas foi escrita em necessidade de bom humor. Brincando. Não há aqui nenhuma intenção precisa de fazer valer um estilo, uma forma, uma escola ou qualquer ortodoxia. A elementar e irreverente maneira de se trabalhar uma série de doze sons e seu abandono sumário servem apenas como estímulo à inventiva e fantasia dos jovens pianistas. É um trabalho dedicado a alunos de piano, esperando que suas características se prestem também à maior desenvoltura e liberdade criativa nos momentos aleatórios apresentados em cada uma das três pequenas peças. Mini Suíte das Três Máquinas não pretende ser uma obra de "vanguarda" nem ser um momento de exibições virtuosísticas. 0 lirismo e poesia interior de cada uma das três máquinas, sim, é que valeriam mais como um convite à imaginação dos intérpretes. Portanto, este trabalho esta mais perto de ser uma proposição do que uma composição. (ESCOBAR, 1977)

0 compositor também integra instruções para a realização de alguns símbolos de grafia utilizados na obra, que revelam a presença de elementos de escrita não tradicional e esclarecimentos sobre os momentos de improvisação presentes na primeira e segunda peças.

$\mathrm{Na}$ "Máquina de Escrever", primeira peça da suíte, o autor trabalha com o dodecafonismo de maneira não ortodoxa, ou seja, repetindo elementos e até mesmo abandonando a própria série em algum trecho (DEL POZZO, 2005, p. 113). A sonoridade e os timbres são muito explorados neste movimento, o autor se utiliza de recursos como clusters variados, appogiaturas, glissandos e um momento de improvisação. Por mais que existam notas escritas de maneira convencional na pauta, a função delas não deixa de ser a de recurso sonoro. Todos estes aspectos da escrita servem para dar à obra o caráter de imitação do som de uma máquina de escrever (DEL POZZO, 2001, p. 147).

A peça Mini Suíte das Três Máquinas, de Escobar - que inclui a "Máquina de Escrever" - fará parte do Recital de Mestrado que realizarei no Programa de Pós

1 Além das atividades como compositor, Aylton Escobar atua também como professor no Departamento de Música da Universidade de São Paulo (USP) e Regente Adjunto da Orquestra de Câmara da Universidade de São Paulo. Em 2010 o compositor defendeu sua tese de doutorado "Richard Wagner: Portal da Regência" pela USP. 
SIMBOLOS DE GRAFIA:

$$
\begin{aligned}
& \text { Com os cinco dedos agrupados, atacar as regiões indicadas. Sons } \\
& \text { indeterminados. "Clusters" de pequeno âmbito. }
\end{aligned}
$$

Todos os acidentes são válidos somente no mesmo compasso ou se os sons estiverem na mesma aliura do mesmo compasso.

Todos os Quadros Aleatórios estão iivres de qualquer indicação prévia para improvisações, salvando-se unicamente a observação dos caracteres expressivos que anteriormente os fizeram inseridos.

AYLTON ESCOBAR

Figura 1. Orientações do compositor Aylton Escobar sobre a escrita não tradicional da peça Mini Suíte das Três Máquinas

Graduação em Música da UFPB. Sendo esta peça o meu primeiro contato com o repertório contemporâneo para piano, muitos desafios surgiram no decorrer do processo de aprendizado. Em um primeiro lugar, a leitura da peça, por não seguir hierarquias harmônicas funcionais, foi árdua, até o momento em que elucidei sua organização sob outros parâmetros, um deles o timbre. Outra questão desafiadora na construção da minha performance foi a realização dos momentos aleatórios, de improvisação. Habituada com o repertório tradicional, a liberdade concedida pelo compositor trouxe em um primeiro momento a sensação de perda, suplantada posteriormente pela satisfação em participar ativamente da construção da peça. Por fim, a dificuldade de memorização, reforçada pela ausência de sentido tonal, parâmetro no qual a memorização do repertório tradicional se baseia fortemente. A minha experiência na construção da interpretação desta peça corrobora com a visão de Gandelman (2000) de que as dificuldades de compreensão e memorização em música contemporânea tem sua gênese na falta de vivência da maioria dos intérpretes com este tipo de literatura, que é, sem sombra de dúvida, extremamente enriquecedora tanto do ponto de vista artístico quanto interpretativo.

\section{Guias de execução}

Dentre a literatura sobre memorização, a obra de Chaffin foi escolhida como referencial teórico principal para este trabalho. Este autor faz parte da linha de pesquisadores que aborda a memorização através da utilização de guias de execução, 
sendo um dos que mais tem se destacado nesta linha de pesquisa. Ele sistematizou em seu trabalho (2002) o processo de memorização por guias de execução através da observação da prática de estudo e memorização de uma pianista de alta performance (CHAFFIN; CRAWFORD; IMREH, 2002). 0 modelo desenvolvido propõe ao intérprete elencar pontos chave da peça para criar uma espécie de mapa mental da mesma, que estará disponível em sua memória de longo prazo para quando for preciso (CHAFFIN; CRAWFORD; IMREH, 2002). Segundo Chaffin, para os músicos a memória envolve a recuperação de pontos cruciais através do emprego de guias instituídos no momento do estudo, ou seja, aspectos da peça nos quais o intérprete focaliza deliberadamente sua atenção sem perturbar a sequência automática dos movimentos (CHAFFIN; IMREH; CRAWFORD, 2002 apud AQUINO, 2011, p. 26).

De acordo com Chaffin, os guias de execução, acima mencionados, "são aspectos que requerem atenção durante a execução" (CHAFFIN, IMREH, 2002, p. 43 apud AQUINO) e ainda pontua que "são as metas expressivas e interpretativas do pianista que devem servir como guias de execução, não os problemas" (CHAFFIN, CRAWFORD, IMREH, 2002, p. 72). Além disso, o autor classifica os guias em quatro diferentes tipos: (1) guias básicos, que dizem respeito à questões técnicas da peça, podendo envolver dedilhados, movimentos do braço necessários para realizar determinada passagem, etc; (2) guias interpretativos, que se aplicam à mudanças dinâmicas, de som e de andamento; (3) guias expressivos, que se referem ao caráter da peça, como sentimentos, atmosferas, etc; e (4) guias estruturais, que delimitam as sessões e subsessões da peça e incluem também os pontos estruturais chamados "switches", que são aqueles nos quais o intérprete deve focar sua atenção, pois com eventual falha podem levar à outra sessão da obra. (CHAFFIN, CRAWFORD, IMREH, 2002, p. 170). Mais além, Chaffin explica que os guias de execução expressivos "representam o mais alto nivel de organização e incorporam o efeito combinado do todos os outros aspectos básicos e interpretativos" (2002, p. 171).

\section{0 timbre na performance}

No artigo, "An exploration of musical communication through expressive use of timbre: The performer's perspective", Holmes traz reflexões acerca da comunicação de emoções em música através do uso do timbre. 0 objetivo principal de sua pesquisa é aprofundar a compreensão da função estética e artística do timbre a partir da perspectiva subjetiva do intérprete. É importante ressaltar que a autora leva em consideração outros pontos cruciais do som além do plano físico deste:

O termo timbre é claramente muito simplista para englobar a complexa sintese que constitui o som instrumental - a 'voz' do artista - na performance. Isso é algo central para o propósito artístico, uma vez que um conceito não é capaz de definir ou quantificar a não ser em um senso geral (tanto artisticamente como na prática da performance). Talvez seja 
a sua dinâmica, sua natureza de mudança que o torne um veículo tão essencial para a imaginação. o estudo científico do timbre continua a prover definições adicionais de suas dimensões. (HOLMES, 2012, p. 317).

Para realizar a investigação, a autora efetuou uma entrevista em modelo semi-estruturado em estilo de conversação com um violonista de alta performance, que fez considerações sobre a sua percepção do timbre como intérprete e também como compositor. As respostas e reflexões do violonista entrevistado foram analisadas através da técnica Interpretative Phenomonological Analysis ${ }^{2}$ e revelaram alguns tópicos relevantes, como: o papel central do timbre na performance; timbre, dicurso e linguagem; timbre e gesto; perspectivas metafóricas; timbre e afeto; e timbre e propósito artístico.

A análise destes tópicos levou a autora a três pontos de destaque em sua conclusão que, de acordo com a mesma, ainda carecem de investigação futura: (1) o engajamento intuitivo do participante com a música (som) parece estar diretamente ligado às suas respostas emocionais à mesma; (2) a manipulação artística do som está no centro da performance em nível de excelência e (3) as observações realizadas pelo participante sobre a preocupação central com o som, aliadas à satisfação do mesmo quando metas sonoras eram atingidas, parecem se aliar às teorias filosóficas que vêem o desejo/vontade e a música como a expressão última de realidades metafísicas.

Dois pontos centrais deste artigo são relevantes para o presente trabalho. Em primeiro lugar, a ideia de que "a variedade de timbres é um dos principais meios pelos quais performers comunicam a estrutura musical, ideias, emoções e personalidade musical" (HOLMES, 2012, p. 301). Tal perspectiva é apoiada pelo fato de que o timbre "aparece como fundamental em qualquer forma de comunicação humana seja o discurso ou a música" (HOLMES, 2012, p. 302).

Em segundo lugar, combinarei os conceitos de McAdams e Seashore apresentados por Holmes (2012) para estabelecer a definição de "timbre" para as reflexões que se seguem. De maneira mais genérica, o timbre é definido por McAdams como "0 atributo da sensação auditiva que distingue dois sons que são iguais em afinação, duração e intensidade" (MCADAMS apud HOLMES, 2012, p. 303). Esta definição é perfeitamente aceitável do ponto de vista físico, porém não representa as propriedades artísticas e potencial expressivo do timbre. Seashore, por sua vez, utiliza o termo "sonância" (sonance) e o define como "as sucessivas mudanças e fusões que tomam lugar em um som de momento para momento" e recomenda esta definição como o entendimento do termo em um contexto musical (SEASHORE apud HOLMES, 2012, p. 303). Neste trabalho o entendimento de timbre levará em conta as perspectivas destes dois autores, abrangendo tanto 0 aspecto físico quanto 0 expressivo de tal parâmetro musical.

2 Técnica de análise e interpretação do discurso (WILLING, 2001/2008, SMITH et al. 1999 apud HOLMES, 2012, p. 309). 


\section{Memorização na "Máquina de Escrever" da Mini Suíte das Três Máquinas de Aylton Escobar}

Pesquisas recentes sobre memória (WILLIAMON, 2006; CHAFFIN, 2002) têm estudado e comparado a memorização de músicos profissionais com a memória de experts em outras áreas. Uma das conclusões básicas que estes autores exibem é que o procedimento de análise da peça é de extrema importância no processo de memorização, pois deste surgirão representações internas ${ }^{3}$ que permitirão ao intérprete recuperar informações da memória (WILLIAMON, 2006, p. 124). Em se tratando de música contemporânea, segundo Gandelman, a análise da obra deve apontar para o modo como os materiais básicos se relacionam e determinam a textura e a forma (2000, p. 107).

Na música contemporânea, o timbre é importante para a comunicabilidade da estrutura e percepção da obra e, ainda, esta propriedade do som pode de fato formar a base da estrutura musical de uma peça (HOLMES, 2011, p. 315-316). Tomando a "Máquina de Escrever" da Mini Suíte das Três Máquinas de Aylton Escobar, pode-se dizer que o material básico da composição é o som e que, portanto, poderíamos pensar na memorização tendo como base aspectos como o timbre, adotando o modelo de memorização proposto por Chaffin (2002).

A partir do que já foi comentado sobre o som como sendo material básico para a construção da obra musical, pode-se relacionar este aspecto ao se pensar na estruturação da "Máquina de Escrever" de Aylton Escobar. Sendo assim, foi possível realizar um mapeamento da peça elencando os diferentes timbres/sonoridades presentes, que também podem operar como possíveis guias de execução expressivos para performance de memória da peça, uma vez que, neste caso, a sonoridade buscada é a meta última do intérprete.

Foram identificados sete timbres principais na construção desta peça. São eles: (1) agrupamentos de semicolcheias de um, dois ou três sons em staccato, (2) clusters de pequeno âmbito, (3) momentos em que a série dodecâfonica é desenvolvida, (4) apoggiaturas, (5) glissando, (6) um acorde tonal e um (7) acorde denominado pelo autor na contracapa como "todo conjunto de sons alterados". Estas sonoridades foram reconhecidas sem levar em consideração o momento de improvisação, no qual o intérprete pode, ou não, adicionar novos timbres.

Para a interpretação de memória da peça, os guias de execução expressivos estariam diretamente ligados com a questão sonora. A tabela 1 mostra um resumo da peça nesses termos. No momento em que o intérprete identifica todos estes timbres e os organiza de acordo com a estrutura da peça, não só a memorização será facilitada, assim como também a compreensão da obra como um todo.

3 "Representações internas, ou representações mentais, são maneiras de "re-presentar" internamente o mundo externo. As pessoas não captam o mundo exterior diretamente, elas constroem representações mentais (quer dizer, internas) dele" (MOREIRA, 1997, p. 1). 


\begin{tabular}{|c|c|}
\hline Frase 1 & Semicolcheias em staccato - Clusters - Apoggiatura - Cluster \\
\hline Frase 2 & $\begin{array}{l}\text { Desenvolvimento da série dodecafônica - Semicolcheias em staccato - Apoggia- } \\
\text { tura - Clissando - Cluster }\end{array}$ \\
\hline Frase 3 & Desenvolvimento da série dodecafônica - Semicolcheias em staccato - Apoggiatura \\
\hline Frase 4 & Desenvolvimento da série dodecafônica - Apoggiaturas \\
\hline Frase 5 & $\begin{array}{l}\text { Improvisação - Apoggiatura - Semicolcheias em staccato - Apoggiaturas - Glis- } \\
\text { sando - Cluster - Apoggiaturas }\end{array}$ \\
\hline Frase 6 & $\begin{array}{l}\text { Semicolcheias em staccato - Clusters - Apoggiaturas - Todo conjunto de sons } \\
\text { alterados - Cluster - Acorde tonal - Cluster }\end{array}$ \\
\hline
\end{tabular}

Tabela 1. Mapeamento de frases da Máquina de Escrever

(Mini-Suite das Três Máquinas), de Aylton Escobar

Feito este mapeamento sonoro, o passo seguinte é selecionar quais deles servirão como guias de execução expressivos, de fato, no momento da performance de memória. Como a peça tem uma estrutura definida, composta por seis frases musicais, proponho que os guias de execução expressivos mais adequados sejam os primeiros e os últimos timbres de cada frase. A escolha destes elementos como guias de execução expressivos tem como fundamento o fato de que a sonoridade inicial e final de cada frase indicam dois aspectos importantes: elas determinam o cárater da frase e auxiliam na condução para a frase seguinte. Além disso, também foram selecionados como guias de execução estruturais a "apoggiatura" e o acorde "todo conjunto de sons alterados" da frase 6 , pois são os elementos que diferenciam esta da frase 1 , evitando que o intéprete se confunda no momento da execução.

Tendo estes guias definidos para o plano mental que auxiliará na memorização, é relevante lembrar que tais sonoridades serão pensadas e alcançadas pelo intéprete através de imagens mentais e metáforas, recursos muito utilizados por executantes durante a construção da performance, que consistem em associar à música, imagens de lugares, situações, imagens auditivas, e imagens da própria estrutura da música, utilizando o que os autores chamam de representações mentais (LISBOA, SANTIACO, 2006, p. 1046). Tais representações são necessárias devido à ausência de um vocabulário que defina as variações de timbre e também devido

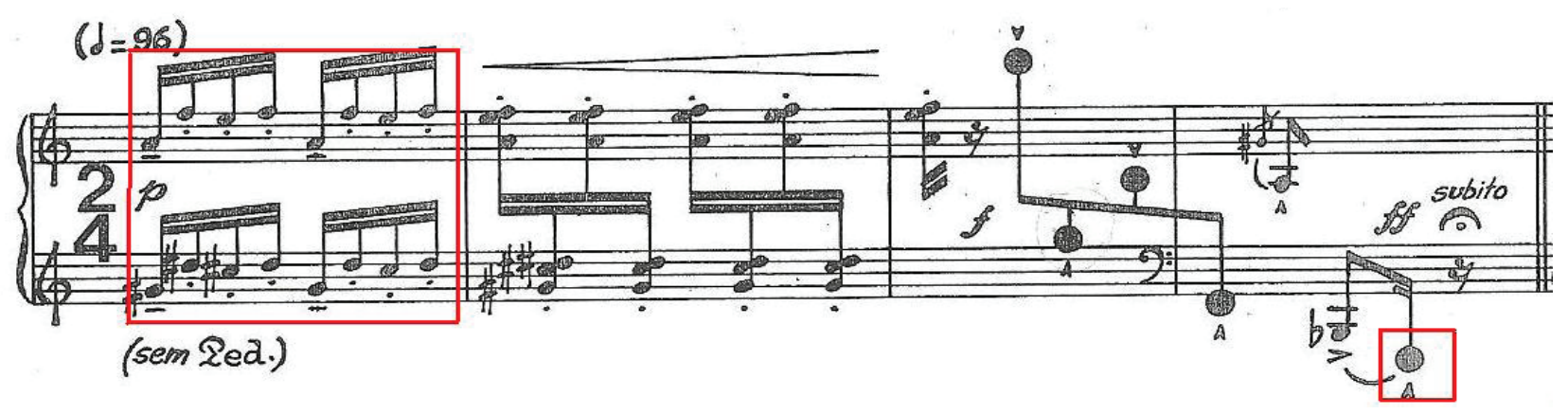

Figura 2. Exemplo de guias de execução expressivos (em vermelho) na Frase 1 da Máquina de Escrever da Mini Suíte das Três Máquinas de Aylton Escobar 


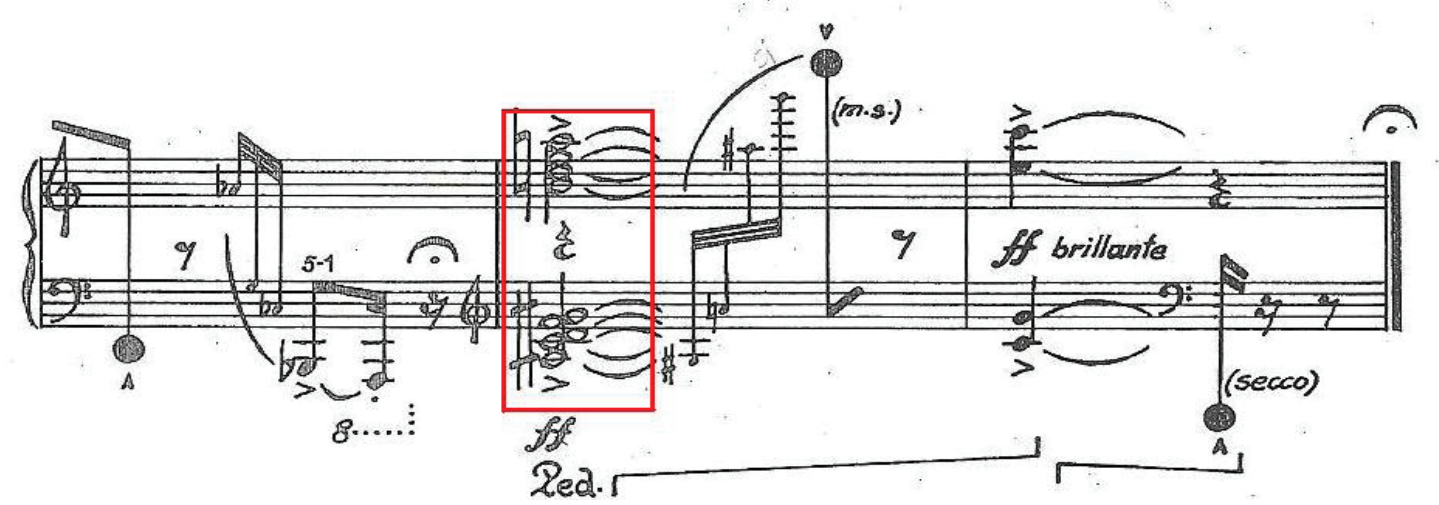

Figura 3 (abaixo). Exemplo de guia de execução estrutural (em vermelho) na Frase 6 da Máquina de Escrever da Mini Suíte das Três Máquinas de Aylton Escobar

ao fato de que tais imagens e a percepção do timbre produzem representações cognitivas semelhantes (HALPERN et al. apud HOLMES, 2012, p. 304).

Desta maneira, o intérprete poderá focar sua atenção nos guias estabelecidos e, dessa forma, alcançar a realização prática destes diferentes timbres na performance de memória da peça, evocando-os através de metáforas pré-estabelecidas. Por exemplo: para os guias de execução relativos ao timbre "semicolcheias em staccato", a imagem evocada poderia ser da digitação em uma máquina de escrever, assim como o timbre relativo ao "glissando" poderia ser evocado através da imagem mental do ato de voltar o carro de uma máquina de escrever. No caso desta peça, bastante descritiva, é possivel entender que os timbres evocam imagens relacionadas à máquina de escrever e à datilografia.

\section{Considerações finais}

As reflexões realizadas neste estudo propuseram uma forma de memorização baseada em aspectos timbrísticos para a performance de memória da peça de Aylton Escobar. A sonoridade (entendida aqui como timbre), neste caso, revelou-se como um possível critério para escolha dos guias de execução expressivos. Pelo fato da peça ser bastante descritiva, as imagens mentais relativas ao som estariam relacionadas à máquina de escrever em si e ao ato de datilografar em uma máquina de escrever. Tendo em mente que o timbre é o aspecto mais relevante na comunicação de emoções em música (HOLMES, 2012), a memorização focada neste parâmetro permitiria uma perfomance mais efetiva no sentido de comunicabilidade expressiva e também mais segura, já que, segundo Chaffin (2002), os guias de execução expressivos são os mais eficazes na recuperação de informações da memória. Além disso, nos mais altos níveis de performance o foco se encontra na música em si mesma, remetendo ao conceito filosófico já mencionado da música como expressão última de realidades metafísicas (HOLMES, 2012, p. 317). 


\section{Memorização para performance da "Máquina de Escrever" da Mini Suíte Das Três Máquinas de Aylton Escobar: uma abordagem a partir do timbre}

Apesar desta pesquisa ter sido realizada tendo uma peça contemporânea como objeto de estudo, é possível que a memorização baseada no timbre também possa ser de grande valia no repertório tradicional ${ }^{4}$. 0 poder do timbre como ferramenta expressiva em formas mais clássicas pode ser maior do que se imagina usualmente, particularmente pelo fato de que a mudança de timbre pode ser mais facilmente ouvida do que descrita (HOLMES, 2012, p. 316). Aliada ao modelo de memorização através de guias de execução, este aspecto expressivo do timbre poderia ser utilizado em prol de uma memorização mais efetiva e comunicativa, tendo guias de execução baseados na sonoridade, pensados pelo intérprete no momento da execução através de metáforas e imagens mentais.

4 Partindo deste pressuposto investigativo, na pesquisa em andamento relativa à minha dissertação de mestrado no Programa de Pós-Graduação em Música da UFPB, a peça adotada como objeto de estudo foi o Op. 1, Variações Abegg, de Robert Schumann. 


\section{Referências}

> AQUINO, Selva Viviana Martinez. Guias de execução na memorização do segundo movimento da Sonata N. 2 de Dmitri Shostakovich. 2011. Dissertação (Mestrado) - Programa de Pós-Graduação em Música da Universidade Federal do Rio Grande do Sul. Porto Alegre 2011.

> BARANCOSKI, Ingrid. A literatura pianística do século XX para o ensino do piano nos níveis básico e intermediário. PER MUSI - Revista Acadêmica de Música, v. 9, p 89-113, 2004.

> CHAFFIN, Roger; IMREH, Gabriela; CRAWFORD, Mary. Practicing perfection: memory and piano performance. Mahwah: Erlbaum, 2002.

> DEL POZZO, Maria Helena. Análise e interpretação da obra para piano de Aylton Escobar. Ictus - Revista Acadêmica de Música, v. 6, 2005, p. 105-121. Questões sobre o universal e o paradoxal na obra para piano de Aylton Escobar. Dissertação de Mestrado - Instituto de Artes, UNICAMP. Campinas: 2001.

> ESCOBAR, Aylton. Mini Suíte das Três Máquinas. São Paulo: Musicália, 1977. 1 partitura. Piano.

> GANDELMAN, Salomea. Memorizando as Variações Op. 27 para piano de Webern: da análise à cognição. PER MUSI - Revista Acadêmica de Música, v. 2, p. 104 $117,2000$.

> GUIGUE, Didier. Estética da Sonoridade, São Paulo, Perspectiva/CNPq/UFPB, 2011.

$>$ HOLMES, Patricia A. An exploration of musical communication through expressive use of timbre: The performer's perspective. Psychology of Music, v. 40, n. 3 , 2012, p. 301-323.

> LISBOA, Christian Alessandro; SANTIAGO, Diana. A utilização das emoções como guia para a performance musical. In: Anais do XVI Congresso da Associação Nacional de Pesquisa e Pós-Graduação em Música - ANPPOM. Brasília: 2006, p. 1045-1048.

> MOREIRA, Marco Antônio. Modelos Mentais. In: Anais do Encontro sobre Teoria e Pesquisa em Ensino de Ciência - Linguagem, Cultura e Cognição. Belo Horizonte: 1997. Disponível em: http://www.if.ufrgs.br/public/ensino/N3/moreira.htm\#inicio. Acesso em 24 de julho de 2012.

> SOLOMOS, Makis. Musique et Bruit. Filigrane nć 7, 2008.

$>$ Prefácio: Do Tom ao Som. In: GUIGUE, Didier. Estética da Sonoridade. São Paulo:

> Perspectiva/CNPq/UFPB, 2011, p. 19-24.

> WILLIAMON, Aaron. Memorizing Music. In: RINK, John. (Ed.). Musical Performance: A Guide to Understanding. Cambridge: Cambridge University Press, 2006, p. 113-126. 
Memorização para performance da "Máquina de Escrever" da Mini Suíte Das Três Máquinas de Aylton Escobar: uma abordagem a partir do timbre

Bibiana Maria Bragagnolo, graduada em Licenciatura em Música e Bacharelado em Piano pela Escola de Música e Belas Artes do Paraná (EMBAP). Atualmente cursa 0 mestrado em Práticas Interpretativas, piano, na UFPB sob orientação da Profa. Dra. Luciana Noda bibi_bragagnolo@hotmail.com 